\title{
Genital Changes, Haemato-biochemical Profile and Therapeutic Management of Endometritis in Crossbred Dairy Cows
}

\author{
L.J. Dutta, R. Deka, K.C. Nath, M. Bhuyan, M. Baruti, D.P. Bora
}

10.18805/IJAR.B-4737

\begin{abstract}
Background: Reproductive performance is one of the major determinants for the economic improvement of a dairy farm. Endometritis and other uterine complications cause decrease the pregnancy rate. In this study, the genital changes and haemato-biochemical profile of crossbred dairy cows affected with endometritis was studied to evolve a suitable treatment protocol in order to improve reproductive efficiency.

Methods: Crossbred cow affected with endometritis were selected based on mucopurulent vaginal discharge at estrus and tested positive for white side test. Animals were divided randomly into 8 groups with 24 animals in each group. Different therapeutic regimens fortified with supportive treatment were opted. The therapeutic regimens were supportive therapy having bypass fat, vitamins and minerals, Lugol's iodine, Lugol's iodine with supportive therapy, intrauterine (IU) antibiotic, IU antibiotic with supportive therapy, E. coli. LPS, E. coli. LPS with supportive therapy and control group respectively. Efficacy of each treatment regimen was based on first service conception rate (FSCR).

Result: Of all the therapeutic regimens, fortification of Lugol's iodine with supportive therapy resulted in higher FSCR (83.33\%) indicating better applicability as a treatment tool for endometritis in crossbred cows.
\end{abstract}

Key words: Conception rate, Crossbred dairy cows, Endometritis, Lugol's iodine.

\section{INTRODUCTION}

High reproductive efficiency of the dairy herd is one of the most essential components to maintain the profitability of the farm. Reproductive disorders in cows reduce their breeding efficiency making them incapable of producing a calf a year. Common reproductive disorders in cattle are anoestrus, repeat breeding, uterine infection, dystocia, ovulatory defects etc. which vary in occurrence with type of animal, breed, parity and level of nutrition and production. Uterine infection is one of the major factors for causing infertility in bovine and inducing irreparable economic losses to the farmers (Drackley et al. 2005). Uterine infections may result in prolonged uterine involution and delayed resumption of post partum ovarian activity. Prevention and treatment of uterine infection is essential for ensuring the profit of the dairy industry.

Uterine infection had been classified as puerperal metritis, clinical endometritis, sub clinical endometritis and pyometra. Clinical endometritis is characterized by purulent (>50\% pus) or mucopurulent (approximately $50 \%$ pus and $50 \%$ mucus) uterine discharge detectable in vagina within 21 days or more post partum without systemic illness (Sheldon et al. 2006). The severity of disease depends on the types of pathogens, genetic factors and immune response of animals (Sheldon et al. 2008). Several Risk factors are associated with the clinical endometritis such as hygiene of the perineum at the time of calving (Schuenemann et al. 2011), peripartum metabolic status (Konyves et al. 2009), retained fetal membranes (Sheldon et al. 2009), delivery of twins and dystocia (Foldi et al. 2006).
Department of Animal Reproduction, Gynaecology and Obstetrics, College of Veterinary Science, Khanapara-781 022, Guwahati, Assam, India.

Corresponding Author: L.J. Dutta, Department of Animal Reproduction, Gynaecology and Obstetrics, College of Veterinary Science, Khanapara-781 022, Guwahati, Assam, India.

Email: drljdutta@gmail.com

How to cite this article: Dutta, L.J., Deka, R., Nath, K.C., Bhuyan, M., Baruti, M. and Bora, D.P. (2022). Genital Changes, Haematobiochemical Profile and Therapeutic Management of Endometritis in Crossbred Dairy Cows. Indian Journal of Animal Research. DOI: $10.18805 /$ IJAR.B-4737.

Submitted: 28-07-2021 Accepted: 08-12-2021 Online: 07-01-2022

Different therapeutic techniques are in practice for treatment of clinical endometritis such as systemic antibiotic administration (Brick et al. 2012) or local antibiotics (Galvao et al. 2019), Lugol's iodine (Ahmed and Elseikh, 2014), $\mathrm{PGF}_{2} \alpha$ and intrauterine dextrose (Kaufmann et al. 2010) or immunomodulators like E. coli Lipopolysaccharide (Bhuyan et al. 2015). However, success rate of these treatment regimens have been found to vary and availability of a cost effective therapeutic managemental protocol for overcoming the endometritis problem in cattle is very much scanty. Hence, the present investigation was conducted to study the genital changes, blood biochemical profile of crossbred dairy cows affected with endometritis and its therapeutic management. 


\section{MATERIALS AND METHODS}

\section{Selection of animals}

The study was conducted in crossbred cows maintained in 100 private dairy farms of North East India during August, 2017 to August, 2020. All the animals were of 60-90 days postpartum at $2^{\text {nd }}$ to $5^{\text {th }}$ lactation having body condition score of 3.5 to 4.5 (Mishra et al. 2016), maintained under semi intensive system of rearing and fed mostly straw, green grasses with small amount of concentrate mixture comprising wheat bran and rice polish.

The animals were considered positive for endometritis on the basis of the following conditions-

a) Mucopurulent vaginal discharge observed at the time of examination.

b) Reported mucopurulent discharge in preceding or present estrus.

c) Vaginal discharge testing positive for white side test (Popov, 1969).

\section{Therapeutic management of endometritic cows}

To study the efficacy of different treatment protocol for addressing endometritis, a total of 192 cows were selected and divided randomly into 8 groups with 24 animals in each group. The treatment protocols were

\section{Group A-supportive treatment}

supportive treatment was started from day of estrus comprising bypass fat (Fatomax, Intas Pharmaceuticals Ltd.) @ $150 \mathrm{~g} /$ day/ animal for 15 days, Mineral mixture (Minfa Gold, Intas Pharmaceuticals Ltd.) @ 30 g/day/animal for 15 days, injectable phosphorus (Tonophosphan Vet, Intervet India Pvt. Ltd.) @ 2 g intramuscularly alternate days for three occasions and Vitamin A (Intavita H, Intas Pharmaceutical Ltd.) @ 25,0000 I.U. intramuscularly for three occasions at alternate days.

\section{Group B-Lugol's lodine (0.25\%)}

Lugol's lodine, $0.25 \%$ solution given intrauterinely with the help of $50 \mathrm{ml}$ syringe and metal uterine catheter on the day of estrus. Lugol's iodine solution was infused into the uterus till the uterus become fully turgid as detected per rectum and the infused solution was expelled out by gentle massage keeping the metal uterine catheter in-situ. After evacuation of the uterus $2 / 3^{\text {rd }}$ of the amount of the solution infused earlier was reinfused into the uterus and kept.

\section{Group C- Lugol's lodine + supportive}

Lugol's lodine, $0.25 \%$ as mentioned under Group B with supportive treatments as mentioned under group $A$.

\section{Group D- Intrauterine (IU) antibiotic}

Lenovo AP IU (Levofloxacin hemihydrates 20 mg+ Ornidazole $40 \mathrm{mg}+$ Alpha Tocopherol acetate $5 \mathrm{mg}$ ), $60 \mathrm{ml}$ infused intrauterinely for 3 consecutive days from the day of estrus.

\section{Group E- IU Antibiotic + supportive}

Lenovo AP as mentioned in Group D along with supportive treatment as mentioned under group $A$.

\section{Group F-LPS}

Single infusion of E. coli. LPS $100 \mu \mathrm{g}$ in $20 \mathrm{ml}$ phosphate buffered saline solution intrauterinely.

\section{Group G- LPS+ supportive}

E. coli. LPS and supportive treatment as mentioned under group A.

\section{Group H}

Control group without any treatment.

\section{Clinico-gynaecological examination}

All the animals were examined per rectum on day 0 (on the day of estrus), and day of subsequent estrus after initiating treatment protocol. On each day of examination, characteristics of vaginal discharge, uterine tone and presence of ovarian structures viz. palpable follicle and palpable corpus luteum (CL) were recorded.

\section{Blood biochemical constituents}

Blood samples were collected on day 0 and day of subsequent estrus after initiating treatment protocol, serum was separated. The blood biochemical constituents like calcium, phosphorus, iron, zinc, level of hormones viz. estrogen and progesterone as well as metabolic hormones like leptin, ghrelin as well as insulin like growth factor-I (IGF-I) were estimated using commercially available kits using manufacturers' instructions.

\section{Post treatment FSCR}

All the cows under treatment groups were subjected to artificial insemination ( $\mathrm{Al}$ ) in the next detected estrus following treatment. Pregnancy diagnosis was confirmed by per rectal examination on 60 days post $\mathrm{Al}$.

\section{Statistical analysis}

Data generated in the present study were analyzed using the SPSS (version 20.0, SPSS, Chicago, IL, USA). Difference with values of $p<0.05$ were considered to be statistically significant.

\section{RESULTS AND DISCUSSION}

\section{Characteristic genital changes}

Characteristic genital changes on day 0 and day of post treatment estrus in crossbred cows affected with endometritis treated using different treatment regimens have been presented in Table 1. All the cows had mucopurulent vaginal discharge on the day of estrus became normal in next subsequent estrus after treating with lugol's iodine + supportive treatment. However, in other treatment groups 16.66 to $37.50 \%$ cows and control group (100\%) cows showed presence of mucopurulant discharge in subsequent estrus. However, Bhardwaz et al. (2018) reported $60.00 \%$ clear discharge at subsequent estrus following intrauterine infusion of Lugol's iodine. In case of intra uterine antibiotic + supportive treatment regime frequency of normal vaginal discharge at post treatment estrus was as high as $83.33 \%$ 


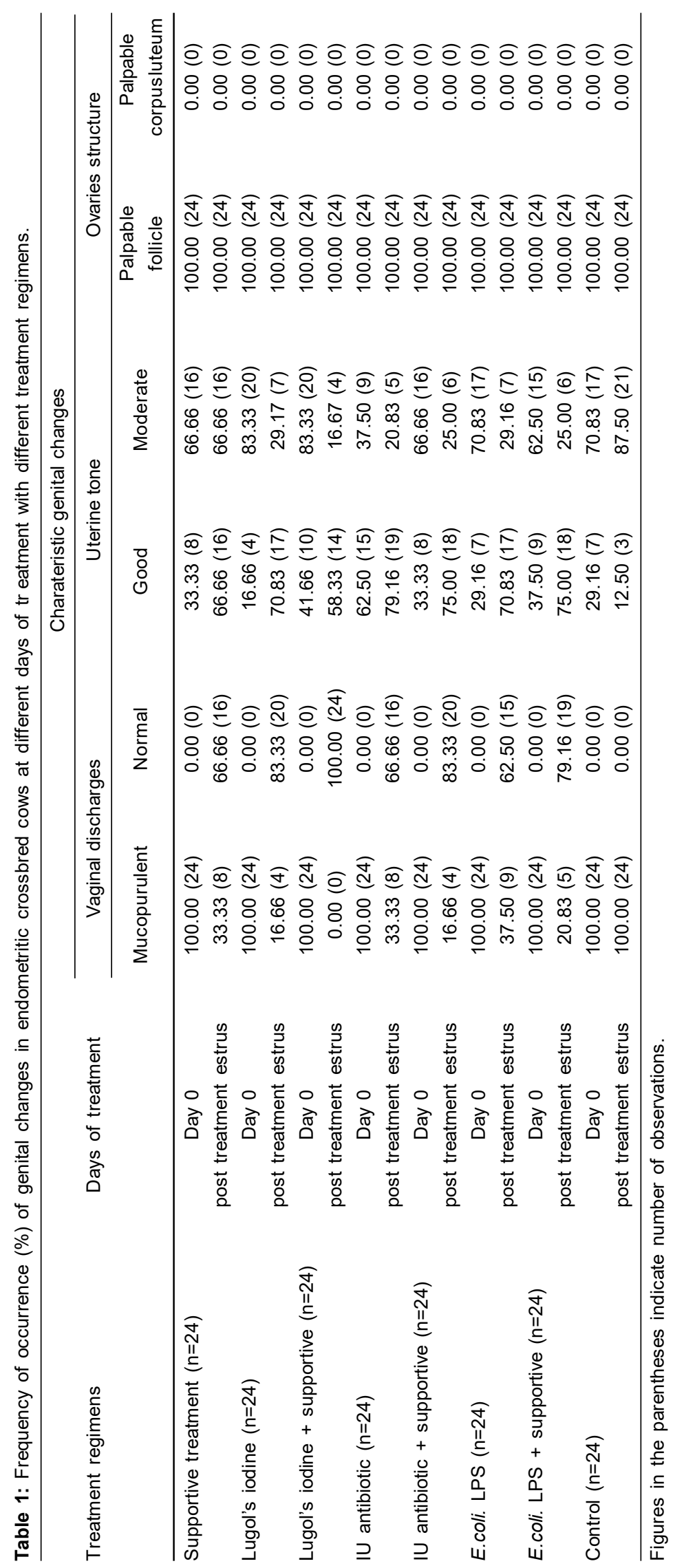


Genital Changes, Haemato-biochemical Profile and Therapeutic Management of Endometritis in Crossbred Dairy Cows

against $66.66 \%$ following treatment with antibiotic alone. Similar result $(70.00 \%)$ was also recorded by Singh et al. (2018a) in endometritic cows treated with intrauterine Ciprofloxacin and tinidazole. E. coli LPS treatment regimen fortified with supportive treatment had beneficial effect in respect of percentage frequency of clear vaginal discharge (79.16\%) as compared to E.coli LPS therapy $(62.50 \%)$. However, Singh et al. (2018a) recorded $80.00 \%$ clear vaginal discharge at subsequent estrus after treatment with $E$. coli LPS in endometritic cows. The clear vaginal mucus following treatment may be due to stimulation of uterine defense mechanism, increased phagocytosis and finally elimination of infection. In control group, all the animals showed mucopurulent vaginal discharge in the subsequent estrus. Similar result was also recorded by Sheldon et al. (2008) in endometritic cows. Presence of mucopurulent vaginal discharge in control group might be due to delay in elimination of infection by natural uterine defense mechanism.

In respect of uterine tonicity, Lugol's iodine and supportive group of animals showed highest $(83.33 \%)$ and control group showed lowest $(12.50 \%)$ uterine tone in post treatment estrus. This might be due to reduced inflammation of endometrium and elimination of pus from the uterus. All the cows had palpable follicle on the day of estrus and subsequent estrus.

\section{Blood biochemical constituents}

Mean serum calcium, phosphorus, iron and zinc at day 0 and post treatment estrus with different treatment regimen in endometritic cows have been presented in Table 2. The mean values for estrogen, progesterone, leptin, ghrelin and IGF-1 are presented on Table 3. Mean value of serum calcium, phosphorus and iron in endometritic cows varied significantly between different treatment regimens on the day of estrus and post treatment estrus, but did not vary between days of treatment. However, serum zinc level did not vary between different treatments regimens on day of estrus and post treatment estrus. These variations were not taken into consideration for comparing the efficacy of different treatment regimens as great individual variations existed among the animals.

The mean value of serum estrogen, progesterone, ghrelin and IGF-1 did not differ significantly between on the day of estrus and post treatment estrus in all the treatment regimens. There is a significant difference between levels of leptin in endometric cows on the day of estrus and post treatment estrus in all the treatment groups except in control group. The value of leptin was found to be increased after treatment in all the treatment groups in the present study. The serum leptin level in fertile and repeat breeder cows was $5.12 \pm 0.43$ and $3.63 \pm 0.25 \mathrm{mg} / \mathrm{dl}$ as reported by Guzel and Tanriverdi, (2014). All the endometritic cows in the present study having 2.08 to $2.92 \mathrm{ng} / \mathrm{ml}$ leptin on day 0 . The post partum reproductive cycle abnormalities were associated with reduced plasma concentration of leptin (Mann et al. 2005). Lower level of leptin resulted negative energy balance and hamper fertility (Jayaprakash et al. 2016).

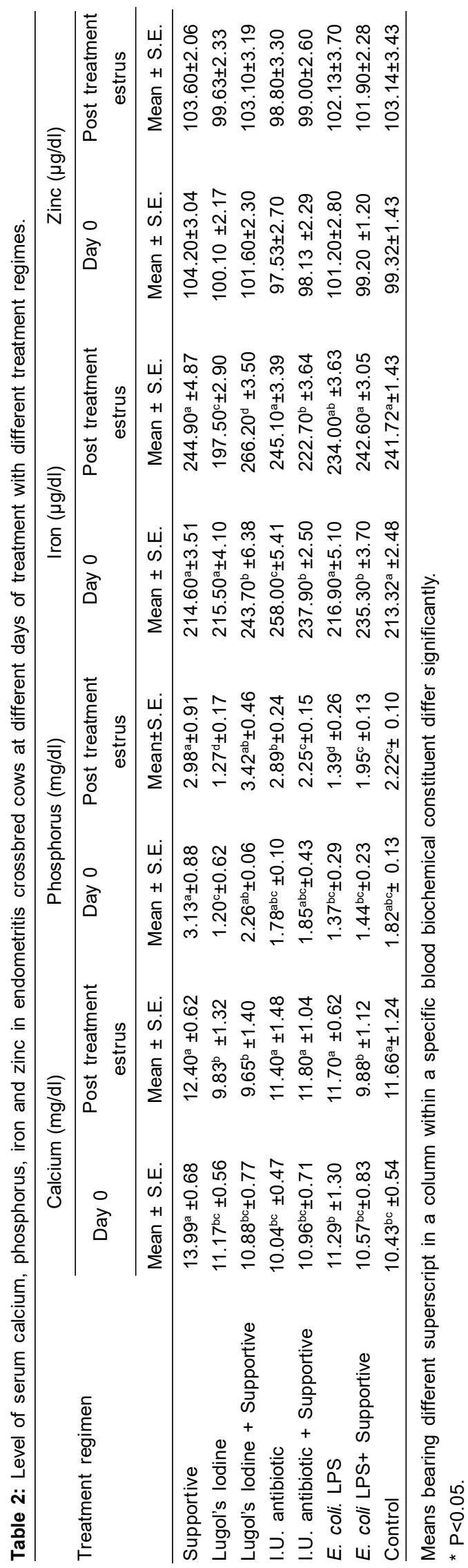

Indian Journal of Animal Research 
Genital Changes, Haemato-biochemical Profile and Therapeutic Management of Endometritis in Crossbred Dairy Cows

From the results obtained in the present study it was difficult to correlate the beneficial effect of supportive treatment on blood biochemical constituents when used for fortification with conventional methods used for treatment endometritis in cows.

\section{Post treatment FSCR}

The post treatments FSCR in endometrtic crossbred cows are presented in Table 4. There was significant difference in the number of animals treated and number of animals conceived in all the treatment regimens. The post treatment FSCR in endometritic cows recorded highest when the cows were treated with lugol's iodine+ supportive (83.33\%) and lowest in the control group $(0.00 \%)$. Perusal of available literature revealed little information on fortification need of therapeutic techniques used for treatment of endometritis in animals for effective comparison of results obtained in the present study. However, role of nutrition on reproductive performance in animals is well established. The FSCR in cows with endometritis treated with $0.25 \%$ Lugol's iodine in the present study was higher $(66.66 \%)$ to Singh et al. (2018b). Conception rate obtained in endometritic cows using different antibiotic was found to vary in wider range. In the present study, $45.83 \%$ conception rate was recorded after treated with IU antibiotics. Similar result (48.28\%) with regards to conception rate has been reported in earlier studies (Singh et al. 2018b) following treatment with intrauterine ciprofloxacin. Moreover, higher post treatment conception rate $(66.67 \%)$ in endometritic cows after treatment with levofloxacin, ornidazole and alpha tocopherol combination was in record (Mishra et al. 2018). The variations in the post treatment conception rate in infectious repeat breeder cows might be due to variation in type of antibiotic, route of administration, dose, degree of sensitivity of antibiotic, severity of uterine infection and time of breeding following treatment (Mosaferi et al. 2013). Intrauterine E coli LPS therapy resulted in $54.16 \%$ conception rate in endometritic cows in the present study. Other reports on use of LPS for treatment of uterine infection in cattle indicated much higher conception rate following treatment ranging from 70.00 to $90.00 \%$ (Singh et al. 2018b). However, lower FSCR $(40.00 \%)$ was recorded by Bhardwaz et al. (2018). In infectious repeat breeder crossbred cows using intrauterine E. coli. LPS. This might have stimulated macrophages and produced interleukin-1 and interleukin-8 that increased the production of granulocyte macrophagecolony stimulating factor for rapid recruitment of polymorphonuclear cells into the uterus and thus cleared the bacteria by phagocytosis process (Methai and Rajasundaram, 2002).

The comparison of results showed fortifications of supportive treatment with lugol's iodine was found to be the best treatment for improving highest FSCR in endometritic cows. Lugol's iodine has benefits like zero withdrawal period, antibacterial, antiviral, antifungal and antiprotozoal properties (Sekhon, 2012). Mineral mixture and by pass fat

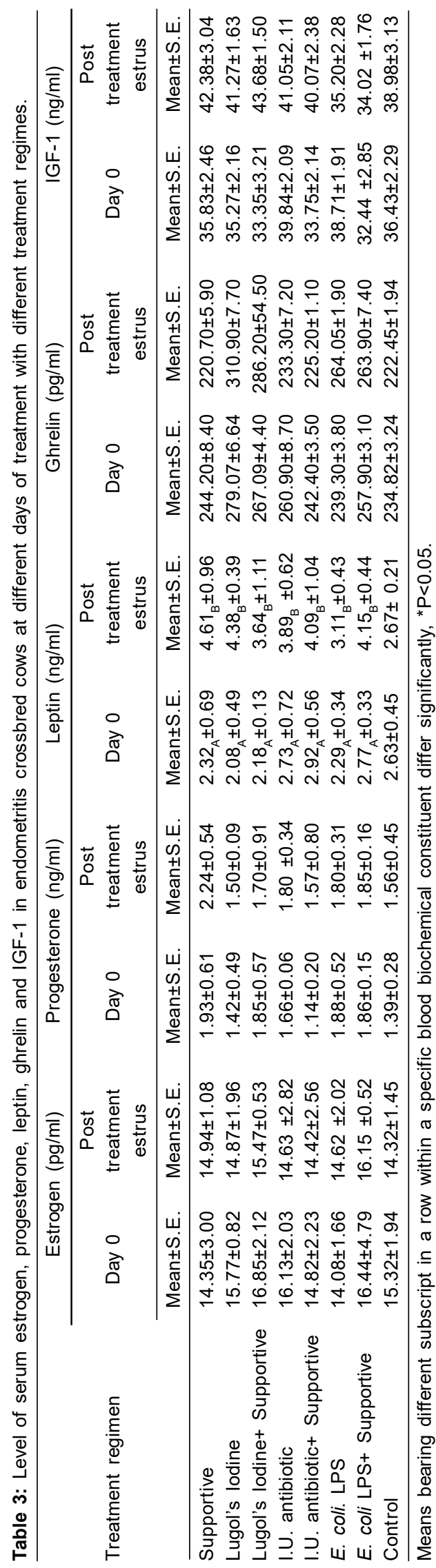


Genital Changes, Haemato-biochemical Profile and Therapeutic Management of Endometritis in Crossbred Dairy Cows

Table 4: First service conception rate in endometritic cross bred cows with different treatment regimens.

\begin{tabular}{lccc}
\hline $\begin{array}{l}\text { Treatment } \\
\text { regimen }\end{array}$ & $\begin{array}{c}\text { No. of animal } \\
\text { treated }\end{array}$ & $\begin{array}{c}\text { No of animal } \\
\text { conceived }\end{array}$ & $\begin{array}{c}\text { FSCR } \\
(\%)\end{array}$ \\
\hline Supportive & 24 & 11 & 45.83 \\
Lugol's lodine & 24 & 16 & 66.66 \\
Lugol'slodine + Supportive & 24 & 20 & 83.33 \\
IU antibiotic & 24 & 11 & 45.83 \\
IU antibiotic + Supportive & 24 & 15 & 62.5 \\
E. coli. LPS & 24 & 13 & 54.16 \\
E. coli LPS + Supportive & 24 & 16 & 66.66 \\
Control & 24 & 0 & 0 \\
${ }^{*}$ P $<0.05$ & & &
\end{tabular}

${ }^{*} \mathrm{P}<0.05$.

supplementation increased growth and reproductive performances of cross bred cattle (Sahoo et al. 2016). Deficiency of Vitamin delays phagocytosis and favors for multiplication of pathogenic micro-organisms in uterus during postpartum period leading to endometritis (Mounir et al. 2017). Therefore fortification of fat, vitamin and minerals along with Lugol's iodine had beneficial effect for treatment of endometritis in cows in relation to FSCR.

\section{CONCLUSION}

It can be concluded that intrauterine Lugol's iodine fortified with supportive treatment used for treating endometritis in crossbred cows resulted in higher FSCR (83.33\%) in comparison to other treatment regimen and all the cows showed normal vaginal discharge at post treatment estrus.

\section{Ethical approval}

Approved by Institutional Animal ethical committee (IAEC), Faculty of Veterinary Science, AAU, Khanapara Campus, Guwahati vide approval number 770/ac/CPCSEA/FVSc/ AAU/IAEC/15-16/291 dated 10/04/2017.

\section{REFERENCES}

Ahmed, F.O. and Elseikh, A.S. (2014). Treatment of repeat breeding in dairy cows with Lugol's lodine. IOSR Journal of Agriculture and Veterinary Science. 7: 22-26.

Bhardwaz, A., Nema, S.P., Mahour, S.S., Bagati, S., Kumar, S. (2018). Therapeutic Efficacy of Lugol's lodine (I2KI) in infectious repeat breeder crossbred cows. International Journal of Current Microbiology and Applied Sciences. 7: 648-654.

Bhuyan, M., Nath, K.C., Deka, B.C., Bhuyan, D., Goswami, S. (2015). Efficacy of E. coli LPS and oyster glycogen in terms of recovery and consequent conception rate in the treatment of metritis in cows. International Journal of Science and Research. 6: 5086-5088.

Brick, T.A., Schuenemann, G.M., Bas, S., Daniels, J.B., Pinto, C.R., Rings, D.M., Rajala-Schultz, P.J. (2012). Effect of intrauterine dextrose or antibiotic therapy on reproductive performance of lactating dairy cows diagnosed with clinical endometritis. Journal of Dairy Science. 95: 1894-905.
Drackley, J.K., Dann, H.M., Neil, D.G., Janovick, G.N.A., Litherland, N.B., Underwood, J.P. Loor, J.J. (2005). Physiological and pathological adaptations in dairy cows that may increase susceptibility to periparturient diseases and disorders. Italian Journal of Animal Science. 4: 323-344.

Foldi, J.M., Kulcsar, A., Pecsi, B., Huyghe, C.J.A., Lohuis, P.C., Huszenicza, G. (2006). Bacterial complications of postpartum uterine involution in cattle. Animal Reproduction Science. 96: 265-281.

Galvao, K.N., Bicalho, R.C., Jeon, S.J. (2019). Symposium review: the uterine microbiome associated with the development of uterine disease in dairy cows. Journal of Dairy Science. 102:11786-97.

Guzel, S. and Tanriverdi, M. (2014).Comparison of serum leptin, glucose, total cholesterol and total protein levels in fertile and repeat breeder cows. Revista. Brasileira de Zootecnia. 43: 643-647.

Jayaprakash, G., Sathiyabarathi, M., Robert, M.A., Tamilmani, T., Azhaguraja, M.(2016). Effect of leptin in dairy cattle. International Journal of Environmental Science and Technology. 5: 1127-1130.

Kaufmann, T., Westermann, S., Drillich, M., Plontzke, J. (2010). Systemic antibiotic treatment of clinical endometritis in dairy cows with ceftiofur or two doses of cloprostenol in a 14-d interval. Animal Reproduction Science. 121: 55-62.

Konyves, L., Szenci, O., Jurkovich, V., Tegzes, L., Tirian, A., Solymosi, N., Gyulay, G., Brydl, E. (2009). Risk assessment of postpartum uterine disease and consequences of puerperal metritis for subsequent metabolic status, reproduction and milk yield in dairy cows. Acta Veterinaria Hungarica. 57: 155-169.

Mann, G.E., Mann, S.J., Blache, D. Webbe, R. (2005). Metabolic variables and plasma leptin concentrations in dairy cows exhibiting reproductive cycle abnormalities identified through milk progesterone monitoring during the post partum period. Animal Reproduction Science. 88: 191-202.

Methai, A. and Rajasundaram, R.C. (2002). Efficacy of Lipopolysaccharide and Plasma in the Treatment of Endometritis in Cows. Comp. XVIII Annual Convention and National Symposium of ISSAR, IVRI, Izatnagar. pp. 83.

Mishra, S., Kumari, K., Dubey, A. (2016). Body condition scoring of dairy cattle: A review, Research and Reviews: The Journal of Veterinary Science. 2: 58-65. 
Mishra, S., Sahu, S.K., Panigrahi, S., Biswal, S.S., Mishra, S.R., Ranjan, R., Mohanty, D.N., Pattnaik, B., Das, S. (2018). Comparative therapeutic efficacy of levofloxacin. Ornidazole and alpha tocopherol combination with prostaglandin $\mathrm{F} 2 \alpha$ on IL6 and IL-10 transcript level in longstanding cases of endometritis in crossbreed Jersey cows. Iranian Journal of Veterinary Research. 19: 217-224.

Mosaferi, S., Davatgar, H., Badie, A.D., Nikniaz, H. (2013). Effect of intrauterine antibiotic injection 24 hours after insemination on conception rate in cows with endometritis. Annals of Biological Research. 4: 312-315.

Mounir, A., Rachid, K., Christian, H., Gary, C.W. (2017). Risk factors of clinical and Subclinical endometritis in cattle: A review. Turkish Journal of Veterinary and Animal Sciences. 41: 1-11.

Popov. Y.N. (1969). Diagnosis of occult endometritis in cows (using white side test on cervical mucus). Veterinary Moscow. 4: 85-87.

Sahoo, J.K., Das, S.K., Sethy, K., Mishra, S.K., Swain, R.K., Mishra, P.C., Satapathy, D. (2016). Effect of supplementation of mineral mixture and bypass fat on performance of crossbred cattle. Indian Journal of Animal Research. 6: 611-618.

Schuenemann, G.M., Nieto, I., Bas, S., Galvao, K.N., Workman, J. (2011). Dairy calving management: Effect of perineal hygiene scores on metritis. Journal of Dairy Science. 94: 744.
Sekhon, B.S. (2012). lodine: A support against infectious and emerging as an antibiotic. Journal of Pharmaceutical Education and Research. 3: 35-39.

Sheldon, I.M., Cronin, J., Goetze, L., Donofrio, G., Schuberth, H.J. (2009). Defining postpartum uterine disease and the mechanisms of infection and immunity in the female reproductive tract in cattle. Biology of Reproduction. 82: 1025-1032.

Sheldon, I.M., Louis, G.S., Leblanc, S., Gilbert, R.O. (2006). Defining post partum uterine disease in cattle. Theriogenology. 65: 1516-1530.

Sheldon, I.M., Williams, E.J., Miller, A.N.A., Nash, D.M., Herath, S. (2008). Uterine diseases in cattle after parturition. Veterinary Journal. 176. 115-121.

Singh, B., Gupta, H.P., Prasad, S., Singh, G.K. (2018a). Effect of uterine defense modulation on recovery and conception rate in endometritic repeat breeding crossbred cows. International Journal of Current Microbiology and Applied Sciences. 7: 105-116.

Singh, M., Sharma, A., Kumar, P., Bhardwaj, N., Sharma, A., Bala, I. (2018b). Studies on clinical efficacy of some therapeutic regimens for the management of endometritis in cows. Exploratory Animal and Medical Research. 8: 110-112. 